\title{
The experiences and needs of female adults with high functioning autism spectrum disorder
}

\begin{abstract}
There is limited large-scale research into the lived experiences of female adults who have an autism spectrum disorder (ASD) with no co-occurring intellectual disability (ID). Drawing on the findings of an Australia-wide survey, this paper presents self-report data from $n=82$ women with high functioning ASD with respect to their health, education, employment, social and community activities. Where relevant, comparisons are provided with the male subset of the same study population: however, in the majority of analyses no discernible gender differences emerged. The findings highlight the diverse and complex challenges faced by women with high functioning ASD, including high levels of mental health disorder, unmet support needs in education settings and the workplace, and social exclusion and isolation.
\end{abstract}

\section{Keywords}

High functioning ASD, females, adults, mental health, masking

\section{Introduction}

Although autism spectrum disorder (ASD) has historically been diagnosed around four times more often in males than females (Whiteley et al. 2010), recent research has challenged the view that ASD is a predominantly 'male' disorder. Epidemiological studies, which apply clinical diagnostic criteria to general population samples, have indicated that actual male to female ratios for ASD prevalence may be as low as 2.5:1 (Kim et al. 2011) or 1.8:1 (Mattila et al. 2011). Overall, the male-female differential has been found to be lower amongst individuals with a comorbid intellectual disability (ID), and more pronounced amongst those without ID (Fombonne et al. 2011).

Further to such findings, it has begun to be argued that the characteristics of ASD are somewhat differently expressed in females compared to males, particularly at the 'high functioning' end of the autism spectrum, and may therefore run the risk of going unrecognised under conventional diagnostic criteria (Mandy et al. 2012; Kreiser \& White 2014). This might help to explain why females with ASD are on average diagnosed at a later age than males (Lai et al. 2011). In one revealing study, Dworzynski et al. (2012) showed that girls who scored highly on a screening test for autistic-like traits were less likely than equivalent scoring boys to meet clinical diagnostic criteria for ASD, especially in the absence of accompanying intellectual or behavioural difficulties. There is related evidence to suggest that some females with ASD symptomatology have been misdiagnosed with conditions such as language delay, anxiety and eating disorders (Hambrook et al. 2008; Coombs et al. 2011; Head et al. 2012).

Recent systematic literature reviews have sought to synthesise emergent findings in this area (Kirkovski et al. 2013; Kreiser \& White 2014; Van Wijngaarden-Cremers et al. 2014). Although there has been considerable variation and inconsistency in outcomes across individual studies, on the whole these reviews suggest some converging evidence for a subtly altered ASD phenotype in females relative to males. Particular points of difference may include (for females) a greater interest in socialisation, fewer stereotypical and repetitive behaviours, restricted interests that are more in line with social and gender norms, and higher levels of comorbid psychopathology and emotional difficulties. More broadly, research has highlighted overlaps between female ASD symptomatology and other conditions, including sleep disorders (Holtmann et al. 2007; Hartley \& Sikora 2009) and eating disturbances (Råstam 2008; Pooni et al. 2012).

It has been suggested that one of the reasons ASD has proved harder to understand and detect in the female population is that females are better able to conceal, or compensate for, aspects of their ASD symptomatology than are males. This theory is known as the 'camouflage' or 'masking' hypothesis (Wing 1981; later Attwood, 2007; Gould \& Ashton-Smith 2011; Ciampi 2013) and is generally discussed in relation to social behaviour. It has been shown that females with ASD have higher natural inclinations towards sociability, emotionality and friendship than do males (Head et al. 2014) and are thus more likely to actively seek conformity with their neurotypical peers, utilising their cognitive skills to generate 'appropriate' social responses and behaviours in a given situation (Attwood 2007). Given that female social interactions commonly revolve around communication and reciprocal sharing of interests (McLennan et al. 1993), key aspects of 'masking' for females with ASD may include rote-learning conversational phrases and using imitation to adapt communication styles to different contexts. 
It has been argued that 'masking' behaviours should be more strongly expected amongst females who have ASD without a comorbid ID, as it is this group that has the cognitive wherewithal both to recognise, and understand how to conceal, their differences (Dworzynski et al. 2012; Kreiser \& White 2014). Notwithstanding, Gould and Ashton-Smith (2011) suggest that the effort involved in perpetual social mimicry and repression of integral 'autistic' behaviour can be mentally and emotionally exhausting and lead to a high incidence of mental health problems for girls and women with ASD. Ultimately, this may only serve to exacerbate, rather than ameliorate, their social isolation.

Kirkovski et al. (2013) conclude their extensive literature review on the female presentation of ASD with the observation that 'an extremely limited knowledge of the female profile is available, potentially leading to inappropriate treatment and management of symptoms for this cohort. It is imperative that future research aims to better understand autism from a female perspective' (p. 2599). To this may be added the comment that the current literature in this area is distinctly biased towards child populations. Research focusing specifically on adult females with ASD is especially limited, with much of the reference literature tending to be anecdotal or autobiographical in nature. There may be a special need to better understand the everyday life experiences of women at the 'high functioning' end of the autism spectrum, who appear to face particular challenges surrounding the recognition and validation of their ASD symptomatology, as well as (potentially) in their efforts to 'mask' their impairments. It is reasonable to assume that both these factors will impact on well-being and functioning in a wide range of life areas.

The present study was intended as a first step towards addressing this gap in current research. Drawing on self-report survey data, its aim was to provide an overview of the health, education, work, social and community activities of a large sample $(n=82)$ of adult females with high functioning ASD. The inclusion of data on a broad range of lived experiences is another feature that distinguishes this research from previous studies - even those involving relatively large samples of females with ASD - which have tended to focus on fairly narrow aspects of symptomatology, cognition, behaviour or health (e.g. Lai et al. 2011; Baron-Cohen et al. 2014). Conversely, the small number of existing large-scale studies investigating the 'everyday life' of adults with ASD have either conflated male and female data together (e.g. Beardon \& Edmonds, 2007) or included participants with wide ranging intellectual ability (e.g. Rosenblatt, 2008), without distinguishing between these groups in the presentation of findings.

A secondary aim of the study was to identify any noteworthy ways in which the experiences of females with high functioning ASD differed from those of a comparable sample of males.

\section{Method}

The present analysis is based on the female subset of participants within a larger study conducted by the authors [citation removed for blinding purposes]. This original study, entitled We Belong, employed a questionnaire methodology to survey the experiences, needs and aspirations of $n=313$ Australian adults who have ASD with no co-occurring ID (referred to hereafter as 'high functioning ASD') in relation to their health, education, work, social and community activities, and daily living. The sample was self-selecting, with adults responding to recruitment notices issued through the [organisation name] website, as well as via [organisation name] service managers to their staff and clients, targeted mailouts to external service providers, contacts and networks in the wider autism community, and selected local, national and online social media outlets. Respondents were given the choice of completing the research questionnaire either electronically or as a paper document.

\section{Participants}

The primary sample for the present analysis includes all female participants in the We Belong study who reported that they had a professional diagnosis of ASD $(n=82)$. All the statistical analyses reported in this paper were also run concurrently on the male subset of the We Belong study participants who reported that they had a professional diagnosis of ASD $(n=200)$. A full breakdown of these comparisons can be found in the Appendix. Any statistically significant differences between the female and male groups are highlighted in the report. Where no such comparisons are drawn, this indicates that there were no significant differences between the male and female subsets on the data items in question.

Demographic information about the female participant group, together with the comparative male sample, is presented in Table 1. From here on, unless otherwise specified, the term 'participants' will refer to the female subset of the We Belong study population only. 
Mean age of the participant group was 32.7 years (SD = 12.3), with a range from 18 to 64 years. Participants were distributed across all eight Australian states and territories, with the highest proportions living in New South Wales (38\%), Queensland (23\%), and Victoria (16\%). The majority $(77 \%)$ lived in urban areas. The group was predominantly (68\%) Australian by birth, with a further $18 \%$ identifying as British or European. Almost all (95\%) spoke English as their first language. Just under half (47\%) lived with one or both of their parents, $29 \%$ lived alone, and $12 \%$ lived with a spouse or partner. Fewer than one in 10 (9\%) had dependent children.

Table 1: Demographic and diagnostic information

\begin{tabular}{|c|c|c|c|}
\hline & Females $(n=82)$ & Males $(n=200)$ & Gender comparison \\
\hline Age (mean) & $\begin{array}{r}32.7 \\
\end{array}$ & $\begin{array}{r}33.2 \\
\end{array}$ & n.s. \\
\hline Age (range) & $18-64$ & $18-70$ & \\
\hline State (\%) & & & \multirow{5}{*}{$\chi^{2}=7.099, p<0.05$} \\
\hline$N S W$ & 38 & 47 & \\
\hline$Q L D$ & 23 & 30 & \\
\hline VIC & 16 & 15 & \\
\hline Other* & 23 & 8 & \\
\hline Region type (\%) & & & \multirow{3}{*}{ n.s. } \\
\hline Urban & 77 & 83 & \\
\hline Rural & 23 & 17 & \\
\hline Cultural background (\%) & & & \multirow{4}{*}{ n.s. } \\
\hline Australian & 68 & 68 & \\
\hline British/European & 18 & 17 & \\
\hline Other* & 14 & 15 & \\
\hline First language & & & \multirow{3}{*}{ n.s. } \\
\hline English & 95 & 96 & \\
\hline Other & 5 & 4 & \\
\hline Living arrangements (\%) & & & \multirow{5}{*}{$\chi^{2}=8.224, p<0.05$} \\
\hline With parent $(s)$ & 47 & 59 & \\
\hline With partner & 12 & 13 & \\
\hline Alone & 29 & 13 & \\
\hline Other* & 12 & 14 & \\
\hline Dependent children (\%) & 9 & 10 & n.s. \\
\hline Diagnosis (\%) & & & \multirow{4}{*}{ n.s. } \\
\hline Autistic Disorder & 81 & 80 & \\
\hline Asperger's Disorder & 17 & 18 & \\
\hline$P D D-N O S$ & 2 & 2 & \\
\hline Age of diagnosis (mean) & 25.0 & 25.5 & n.s. \\
\hline Age of diagnosis (range) & $2-63$ & $2-66$ & n.s. \\
\hline Age of diagnosis (grouped \%) & & & \multirow{3}{*}{ n.s. } \\
\hline Under 18 & 42 & 44 & \\
\hline 18 and over & 58 & 56 & \\
\hline
\end{tabular}

As Table 1 indicates, the female and male subgroups of the We Belong study were comparable in all respects except for geographical distribution and living arrangements. Male participants tended to be concentrated in New South Wales and Queensland, while females were more broadly distributed across Australian states and territories. Females were more likely than males to live alone, and less likely to live with one or both of their parents.

\section{Notes on sample validity}

The scale of the We Belong study, together with the survey methodology employed, necessitated a reliance on participants self-reporting that they had an ASD. Whilst the authors had no direct means of 
verifying the accuracy of these self-reports, several measures were put in place to ensure the integrity of the sample as far as possible.

1. Participants were asked to specify the type of ASD diagnosis they had received (or their most recent diagnosis if they had received more than one): namely, Autistic disorder, Asperger's disorder, or PDDNOS. 1

2. Participants were given the option of stating that while they personally believed they had an ASD, they had never received a professional diagnosis. Participants who gave this response were excluded from analysis for the present study.

3. Participants who indicated that they had a professional diagnosis of ASD were asked to state the age at which they had received this diagnosis. Within the overall We Belong study population, $78 \%$ of participants were able to state their age of diagnosis; within the female subset of participants included in the present study, this proportion increased to $92 \%$.

Another in-principle limitation of the study was its reliance on participants' self-selection on the basis that they did not have ID. A guideline for determining the presence or absence of ID (an IQ of below or above 70, respectively) was provided in an explanatory note accompanying the research questionnaire, and potential participants were encouraged to contact a psychologist from the research team for further advice if they were unsure whether or not they had ID. Whilst this initial screening mechanism could only be successful in proportion to the self-awareness and cooperation of respondents, from this point on there were intrinsic features of the study methodology that would almost certainly have presented challenges for an individual with ID seeking to participate. As a paper document, the research questionnaire was 16 pages in length and would have required considerable concentration and engagement to complete; and the questions themselves, whilst designed to be as clear and concise as possible, were worded and constructed at a level appropriate for a highly literate adult.

Once the survey responses had been collated and analysed, there were several elements of the data that strongly implied the study sample should indeed be considered 'high functioning': in particular, the fact that $86 \%$ of participants had attained post-school educational or training qualifications.

\section{Measures}

The research questionnaire was devised in consultation with an advisory group that included ASD specialists and educators, an adult with ASD, and a parent of an adult with ASD. It consisted of 28 items divided across six main sections, namely (1) health and wellbeing, (2) education, (3) employment, (4) social and community activities, (5) support needs, and (6) future aspirations. Each section employed a mix of question and answer formats, including 'tick-box' choices, written factual information, Likert-style response scales, and open comments. In some cases, a response framework was provided for the open comment sections, for example: Please briefly describe the three best things about your time in education. This report presents a selective summary and analysis of data drawn from across all six areas of the questionnaire.

\section{Analysis}

A mix of descriptive, statistical and thematic analysis methods were applied to different aspects of the data. These are highlighted through the course of the report as relevant.

Thematic analysis was applied to the 'open comments' data received through the survey, and involved devising coding frameworks to group responses into broad categories of related information. For example, responses to the question: Please briefly describe the three best things about your time in education yielded seven broad categories of responses, including 'learning and studying', 'friendships and socialising' and 'teachers and support systems'.

\footnotetext{
${ }^{1}$ These categories correspond to the diagnostic sub-groupings for Pervasive Developmental Disorders in DSM-IV-TR, which was still in use at the time of the study. It was succeeded by DSM-5 in May 2013. DSM-5 states that individuals with a well-established diagnosis based on a previous edition of the manual (i.e. of Autistic disorder, Asperger's disorder, or PDD-NOS) are eligible for the DSM-5 diagnosis.
} 
Results of the thematic analysis are presented as qualitative summaries of broad themes evident in the open comments. These are intended to be illustrative rather than 'scientific', and to augment the quantitative data presented in the report.

A further level of analysis was applied to the survey data on employment, in order to gauge whether participants were educationally over- or under-qualified relative to the skill requirements of their current job. Based on their self-reported job titles and work descriptions, each participant was assigned to an occupational grouping according to the Australian and New Zealand Standard Classification of Occupations (ANZSCO) system. Every occupational unit group listed within ANZSCO is aligned with a 'skill level', defined primarily by the level of formal education and training required for competent performance of an occupation. By mapping the skill level of an individual's job against their highest held educational qualification, it is possible to classify them as 'overeducated' or 'undereducated', depending upon whether their highest qualification falls above or below the designated skill level of their current job.

\section{Note on comparative statistics}

At points of this report, comparisons are drawn between aspects of the study findings and related data from other research or public sources. The aim of these comparisons is to highlight characteristics of the high functioning female ASD population that may broadly resemble, or differ from, the Australian population as a whole. It is cautioned that, in view of the complexities and nuances underlying the way in which terms are defined, data gathered, and statistics calculated across different organisations and research exercises, any such comparisons should be treated as indicative rather than exact or conclusive.

\section{Results}

\section{Diagnosis and ASD symptomatology}

The majority (81\%) of participants stated that they had a diagnosis of Asperger's Disorder, with much smaller proportions reporting a diagnosis of Autistic Disorder (17\%) or PDD-NOS (2\%). ${ }^{2}$

Over half (58\%) of participants reported that they had received their diagnosis at or after the age of 18, with the mean age of diagnosis being 25.0 years. These figures exclude those participants who indicated that they did not know, or could not remember, at what age they were diagnosed $(9 \%)$.

Thematic analysis of open comments revealed a recurrent belief that life would have been much easier if diagnosis had been confirmed earlier and more support provided from a young age.

The last 14 years have been a quest for me to understand what is different about me, why normal things don't seem normal to me. Getting the Asperger's diagnosis was at the end of a long search and has made sense of a lot of things through my life.

My kindergarten suggested I get assessed, and I was deemed retarded as I wouldn't participate in the stupid assessment which was done in baby talk and baby games. The ignored the fact I could already play chess and read books considered too advanced for me. I avoided professional help due to my experiences as a child.

It wasn't until high school that anyone suggested I may have Asperger's. The specialist I saw insisted I didn't have it, he just saw it as a 'conformist label for eccentricity', so while he thought he was doing me a favour I continued high school without proper support. It was only this year in university that I was properly diagnosed and supported.

I have had lifelong problems with eating (due to sensory issues) misdiagnosed and was therefore wrongly treated for 25 years prior to ASD diagnosis.

I was depressed for a long time. To have had access to a skilled psychologist when I was younger, who understands Asperger's, would have been very helpful.

\footnotetext{
${ }^{2}$ Percentage breakdowns may not sum to 100 due to rounding.
} 
Even though I have known I am 'wrong' for a very long time, it has only been the last couple of years that I suspected I had Asperger's. I received a formal diagnosis this month and am just going through the motions of feeling relief, anger and a certain amount of confusion. Now that I understand the reason for my differences (I am not calling them disabilities) I can see clearly that a little help much earlier would have been incredibly useful.

Across the open responses recorded in the survey, two prominent themes emerged with regard to the experience of ASD symptomatology: (1) difficulties with executive functioning, and (2) difficulties in social understanding and communication. In addition (although not part of the official diagnostic criteria for ASD), stress and anxiety were very common. These themes are elaborated in the following sections.

Smaller numbers of open comments included references to sensory processing difficulties, such as hypersensitivity to light or sound and intolerance of physical touch. A minority also alluded to OCD-type behaviours, including 'perfectionism'.

\section{Health and mental health}

There was a high prevalence of self-reported mental health concerns within the participant group, with $82 \%$ answering 'yes' to the question: Do you consider yourself to experience frequent worry or stress? and $85 \%$ answering 'yes' to the question: Do you consider yourself to have a mental health condition (such as anxiety or depression)? These figures contrast strongly with government population statistics indicating that, within a 12 month period prior to being surveyed, $5 \%$ of Australian females had a self-reported depressive episode while $18 \%$ experienced symptoms of anxiety (Slade et al. 2007).

Through further thematic analysis of participants' open comments, stress and anxiety were found to be common and debilitating factors across all areas of life addressed in the survey, including study, work, and social interaction. However, depression was mentioned less regularly in this regard.

Almost three-quarters (73\%) of participants answered 'yes' to the question of whether they needed ongoing professional support for mental health and wellbeing, and of this group, $30 \%$ indicated that they were not currently receiving an adequate level of support.

In response to an open question about physical health and wellbeing, the two most common areas of concern mentioned by participants were gastrointestinal complaints and sleep disorders.

Comparison with male participants. Within the overall We Belong study sample, a significantly higher proportion of females $(85 \%)$ than males $(67 \%)$ reported that they believed they had a clinical mental health condition $\left(\chi^{2}=9.160, p<0.05\right)$.

\section{Education}

Asked to list their educational attainments, $82 \%$ of participants reported having completed Year 12 or an equivalent level of education: a figure relatively close to that for the female Australian population as a whole, namely $89 \%$ (ABS 2014). Contained within this group, $11 \%$ of the overall sample held a Bachelor degree or higher qualification: a lower proportion than the $29 \%$ of all Australian females educated to degree level or above (ABS 2014).

A little under half (43\%) of participants were enrolled in a course of study at the time of the survey: $17 \%$ on a full-time basis and $26 \%$ on a part-time basis.

Half (51\%) of participants answered 'yes' to the question: Do you consider yourself to have learning difficulties?, while over half (53\%) answered 'yes' to the question: Do you consider yourself to have problems with attention and concentration? In a separate, multiple-choice section of the questionnaire pertaining to ongoing and everyday support needs, $38 \%$ of participants ticked 'improving study skills' as an area for which they required support. Thematic analysis of open comments revealed that participants had typically struggled with the executive functioning demands of formal learning. These challenges included maintaining concentration, understanding complex or ambiguous language, listening and taking notes simultaneously, meeting assignment deadlines, and preparing for and sitting tests and exams.

In response to the open question: Please briefly describe the three best things about your time in education, $32 \%$ of participants provided at least one comment pertaining to positive experiences of support received 
during their school and university years, both through formal structures (such as support classes) and informal channels (such as understanding and helpful teachers). Conversely, however, $46 \%$ cited a lack of support as one of the three 'worst things' about their time in education. There was considerable overlap between these two categories of respondents, suggesting that even for those who had benefited from support mechanisms in education, these experiences were often inconsistent across different ages or settings.

In response to a question focusing on specific types of support received during their formal education (inclusive of primary, secondary and tertiary level), 51\% of participants stated that they had not received sufficient support for studying and learning; $68 \%$ recalled an inadequate level of support to help them regulate problem behaviours; and $77 \%$ indicated that they had not received enough support to make friends and develop social skills.

Participants who were diagnosed with ASD at or after the age of 18 were significantly more likely (91\%) than those diagnosed before age $18(61 \%)$ to state that they had not received enough social support during their time at school $\left(\chi^{2}=9.192, p<0.01\right)$. Age of diagnosis made no difference to perceptions of support for learning or behaviour. Overall, those diagnosed before and after the age of 18 were equally likely to refer to 'lack of support' as one of the worst things about their time in education.

As the following quotes (derived from the open comments) illustrate, many of the women in the study were evidently recognised as being 'different' by their teachers. However, it appears that their difficulties were frequently overlooked or dismissed, especially if they were academically able.

Teachers noticed I was odd but never figured out that I have Asperger's.

I obviously had severe learning disabilities (undiagnosed because of my age) but also did well so was nagged to try more.

[There were] very clear signs that I needed significant support throughout education, but I got none because my marks were very good.

I never received adequate help for issues as I appeared 'capable', and therefore issues were downplayed.

When I told teachers that I had some kind of learning problem they laughed at me.

I was alone with the constant struggling, having no idea why I felt and behaved the way I did. I was told that I was simply too 'dramatic' or 'sensitive'.

Some participants were also affected by the reverse of this situation, namely that their specific abilities and skills seemed to go unrecognised and they did not feel academically stretched or stimulated.

I loathed that I couldn't do subjects I was interested in.

Classes were dumbed down to the lowest common denominator.

I hated being told what I needed to learn.

At times I have known more about the subject than my teachers, but I struggled to complete subjects purely because of social reasons.

I remember being accused of cheating when handing up complete, original and pristine projects.

It was evident that peer relationships had proved extremely difficult during participants' education years. In response to the question: Please briefly describe the three worst things about your time in education, $50 \%$ referred directly to having been bullied or teased at school. A further one-third (37\%) mentioned feeling lonely, isolated or excluded, or struggling to make and keep friends. Notwithstanding that this is a complex topic to gather statistics on, these figures tentatively suggest a higher rate of perceived bullying amongst the female ASD population than more broadly amongst Australian school students: a 2006 study by the Australian Government reported that $27 \%$ of primary and secondary students had experienced some form of bullying (Cross et al. 2006). 
Comparison with male participants. A significantly higher proportion of females (43\%) than males $(27 \%)$ were enrolled in a course of study at the time of the survey $\left(\chi^{2}=6.721, p<0.01\right)$.

A significantly higher proportion of females (77\%) than males (65\%) stated that they had received an inadequate level of social support during their time in education $\left(\chi^{2}=3.846, p<0.05\right)$.

\section{Employment}

Of those participants not enrolled in full-time education at the time of the survey, $62 \%$ had a paid job. This figure stands substantially below the $95 \%$ national employment rate for Australian women in the same year (ABS 2013). Within this group, $60 \%$ were working part-time and $41 \%$ full-time.

The highest proportions of participants were employed in the occupational groupings 'community and personal service workers' (24\%), 'clerical and administrative workers' (24\%), 'professionals' $(22 \%)$ and 'technicians and trades workers' (12\%). Over half (55\%) held educational qualifications that exceeded the skill requirements of their current job. This 'overeducation' rate again greatly exceeds the corresponding figure of $24 \%$ calculated for employed Australian women as a whole (Black 2013).

Thematic analysis of participants' open comments about their work experiences exposed a recurrent theme that they had felt 'pinned back' from fulfilling their job and career potential. Similar to their time in education, they perceived that their abilities and skills would often go unrecognised or be devalued in the workplace.

One of the worst things was having to follow rules even when I came up with ways that got the job done quicker.

Being smarter than others, an incredibly high IQ, but being treated like an idiot.

I resent having people assume I'm a secretary and not know about my scientific mind.

Progression is only through an interview process and I cannot do interviews.

I struggled to understand what I did wrong and why my abilities were not valued when I could often manage tasks better than my colleagues.

The social aspects of work also presented a significant challenge to this group, with $60 \%$ mentioning this as one of the 'three worst things' about their employment experiences to date. Ostensibly simple communication tasks, such as exchanging pleasantries with colleagues or answering the telephone, could feel overwhelming. Worse still were more 'formal' requirements for interpersonal interaction, such as meetings, group work, line management, or client-facing tasks.

I find being around people all the time incredibly draining.

I don't like interacting with people I can't 'read'.

The worst thing is the constant requirement for social interaction with others and 'chit-chat'.

My resting anxiety levels get quite high when I have to provide feedback to staff.

I stress about missing body language cues from clients and staff and making a stuff up.

Bullying and overt mistreatment by others did not appear to be as prevalent in the workplace as they had been in educational settings, but were still mentioned by almost one-quarter (23\%) of participants in response to the 'three worst things' question.

Some people find it amusing to tell jokes around me, then roll their eyes and not explain.

The boss/owner told me nobody else would hire me because I have Asperger's.

People are not shy in telling me that I should not be working because I am mad/weird/different. 
Once again, it was evident that executive function deficits had played a strong part in the challenges experienced by participants at work. These manifested in various ways, including difficulties in comprehending tasks and following instructions, as well as in cognitive 'overload' in some circumstances.

I disliked fast paced work where I was expected to know what was required.

There is not enough guidance or clearly explained procedures.

I'm sometimes not able to meet deadlines because I'm physically slower than the average person and I can't work out difficult tasks quickly.

Our pharmacy is in a busy shopping centre - the noise and activity is extreme. I have a meltdown (carefully hidden as much as possible) every week on average.

I experience cognitive shutdown and often meltdown as the day goes on, and have to just keep working.

Fewer than one-third (29\%) of employed participants answered 'yes' to the question: Are you currently receiving any support in the workplace for your autism spectrum disorder? Some of the support mechanisms mentioned included assistance from external agencies, adjustments made within the work environment or to job tasks (e.g. special lighting to accommodate sensory sensitivities), and personal support and understanding from managers or co-workers. The same proportion of participants (29\%, with some overlap between the two groups) answered 'yes' to the question: Would you like to have more support at work? Those who provided additional information in response to this question variously spoke of their desire for greater understanding by others, more flexibility in their work tasks or hours, and help with developing skills and strategies in areas such as communication and coping with change.

Of the $38 \%$ of participants not currently employed (and not studying full-time), $56 \%$ stated that they would prefer to have a job. This equates to a $15 \%$ 'involuntary unemployment' rate for the study population as a whole. The majority (86\%) of this group indicated a preference for part-time work, which contrasts with recent population statistics indicating that $39 \%$ of unemployed females would prefer parttime work (ABS 2012). However, a review of the open comments on this topic indicated that securing part-time work was not always a straightforward option.

I know I can never work full-time and do everything other people take for granted.

It's hard to find jobs that let me work few enough hours that I can manage.

[My organisation] only ever offered permanent full-time or casual part-time, never permanent part-time.

I would like to have a part-time job that I like and I feel fulfilled with. Yet I need help with finding one.

Notwithstanding their challenging and negative experiences in the workplace, many women in the study remained upbeat and ambitious with regard to their future plans, with plenty of aspirations to further study and new careers. A number expressed interest in creative pursuits, such as writing, visual and performing arts. It was clear, however, that many needed the help and support of others if they were to achieve their goals.

I am lacking the networking skills which seem more important where I live than any qualifications you have.

There are some big things I would like to do with massage that would help a lot of people - but I know I don't have the skills to bring all the aspects together, or the skills to work closely enough with someone else who can help with that.

I want to become a photographer for a magazine but haven't been able to motivate myself to make and submit a portfolio. 
I plan to run my own business from home, but even joining an agency wasn't helpful, there aren't enough specialised services to provide support.

My hopes for having a career or working life have faded. I could have done with some help earlier in my life to direct me into a suitable career.

Comparison with male participants. A significantly higher proportion of females (60\%) than males $(40 \%)$ identified difficulties with social interaction as one of the three worst aspects of their employment experiences to date $\left(\chi^{2}=7.419, \mathrm{p}<0.05\right)$.

As noted above, $86 \%$ of females who were unemployed but desiring a job stated a preference for parttime work. Unemployed males were significantly less likely (51\%) to state a preference for part-time work $\left(\chi^{2}=7.419, \mathrm{p}<0.05\right)$.

\section{Social experiences}

In response to the question: How satisfied are you with your social life at the moment?, the majority (80\%) of participants ticked 'very satisfied' or 'fairly satisfied'. There was some measured interest in becoming more involved in social and community activities: $36 \%$ of participants stated that they would like to be (but were not currently) involved in a social group or club, $32 \%$ would like to have a regular group of friends; and $32 \%$ would like to meet with a mentor or befriender. Conversely, over one-quarter $(27 \%)$ of participants stated that they preferred to be alone than in the company of others.

Of those participants not already in a romantic relationship, over half (56\%) included 'dating and relationships' as one of the areas in which they would like more support. However, fewer than one in five (19\%) of this group listed marriage or a relationship as one of their top three hopes and aspirations for the future.

A number of the open comments recorded across the survey suggested that the women had actively sought (or, at least, identified a need) to 'learn' aspects of communication and social behaviour that would enable them to relate to others in a way that would be perceived as appropriate.

I was unable to understand the inane 'rules' of teenage girls which meant I was continually saying/doing the wrong thing.

I have learned to act and developed a list of public responses I refer to. This stops me being too honest and logical at initial conversations. I still think what I like, but mask it behind a smile.

I had to study acting to appear as normal for the customers.

I need to know how to think before I speak, so I don't hurt the feelings of others.

I would like to have some basic knowledge of social skill etiquette so I can be with a group of friends comfortably, without feeling self-conscious about making a mistake.

I would like to learn skills for overcoming shyness.

Learning how to be social doesn't make it easier or less stressful because it's still against my natural grain. If I behave in a socially normal way, then that's how people perceive me, and I have to keep up that standard, which is impossible.

Reflective of these statements, $62 \%$ of participants reported that they needed support to improve their social skills, and $44 \%$ expressed a need for support to help deal with bullying and discrimination.

Comparison with male participants. Females were more likely (27\%) than men (10\%) to state that they preferred their own company $\left(\chi^{2}=14.288, \mathrm{p}<0.01\right)$.

Females were significantly less likely (19\%) than males (40\%) to list marriage or a romantic relationship as one of their top three hopes and aspirations for the future $\left(\chi^{2}=8.139, p<0.05\right)$. 
Only one male respondent touched on the theme of 'learning' appropriate social behaviour as a means of counteracting social exclusion. Overall, males tended to report their experiences of social isolation and illtreatment in a relatively factual manner.

\section{General support needs}

Finally, participants supplied a range of comments, not directly solicited, that expressed a sense of ongoing struggle to cope with everyday life, and the lack of recognition and support available to help them.

I really struggle with the basic tasks of anything (e.g. cooking, domestics). I can usually find a way to do it, but it doesn't come easily.

I feel like I am struggling just to get by. I know that I am not receiving the support that I need, but I really don't know of any way to change that.

I wish I could feel like I am not just trying to survive, and find the support that I need.

I don't feel like the daily struggles of adults with Asperger's are well understood. I fight through (and hide, as best I can) a relentless struggle. I often feel like I just can't keep going.

It seems like if you have a job and live alone, no-one thinks you might still need help. In my experience, you cannot access help until you reach rock bottom. I was only able to get support when I had such crippling anxiety that I could not go shopping or even leave the house. If they had given me support earlier it would have been easier to get back on track again.

I believe that as a person who is perceived as 'high functioning', others tend to downplay my difficulties because they are not as obvious. I find that frustrating because there are some areas where it may seem like I am functioning well, when in reality performing in those areas is stressful for me. I tend to fall between the cracks regarding services - I am not seen as requiring assistance, when in reality I do.

\section{Discussion}

This study contributes to the growing body of research data on the female presentation and experience of ASD, and addresses a specific niche in this field by focusing specifically on (1) adults, and (2) those without ID. It is this 'high functioning' female group that has been identified in earlier research as being particularly susceptible to non-recognition and misdiagnosis, and to the complications arising from efforts to 'mask' their social and communication difficulties (Attwood, 2007; Gould \& Ashton-Smith 2011; Head 2014).

An important and overarching observation to make from the study data is that there were only a minority of instances in which females differed from males on quantifiable outcome measures. This supports previous research indicating that there is not so much a unique 'female profile' of high functioning ASD, as a range of subtle and subjective ways in which the disorder manifests itself and is experienced by women that may differ from the corresponding experiences of men. This suggests that qualitative, anecdotal and autobiographical data will continue to make a valuable contribution to this field of research.

The findings of this study lend support to the notion that many females now confirmed to have high functioning ASD have been historically disadvantaged by a lack of timely or accurate diagnosis. Participants whose ASD had long gone unrecognised lamented the lack of support and compassion shown for their needs, particularly during their school years, but also continuing into the workforce and other areas of adult life. In some cases this was only compounded by the internal confusion and distress of not understanding why they were 'different'. The ongoing need to improve coverage and accuracy for early diagnosis of ASD in females - particularly those without obvious intellectual or behavioural challenges is very evident.

Mental health is clearly a significant area of concern for this population, and is one area that stands out as specially pertinent to females with high functioning ASD vis-à-vis males. In addition to a high prevalence of self-reported mental health conditions within the study sample, a large majority experienced ongoing feelings of worry and stress that seriously impacted their everyday functioning. In spite of this prevailing 
issue, it appears that many women with ASD either do not or cannot access satisfactory professional support to help them regulate or improve their mental health and wellbeing. These findings point to the need for specialised counselling, psychology and social support services that are attuned to the close relationship between ASD and anxiety in high functioning females, and could contribute to improved mental health and quality of life outcomes for this group.

In addition to highlighting the comparatively high educational attainments of women with high functioning ASD, the fact that close to half participants were undertaking some form of education or study at the time of the survey reinforces that this is a group with strong interest in and aptitude for learning. At the same time, this study provides insight into the significant struggles many women with ASD have experienced during their time in education. A clear implication of the study findings is that the absence of ID does not equate to an absence of learning support needs. As noted above, many of the women in the study failed to have these needs properly understood or met while at school, and have continued to require support in adult education to cope with the demands of formal learning. Another significant blight on the educational experiences of women with high functioning ASD has been the victimisation and exclusion they have endured at the hands of fellow students; and, in some cases, teaching staff. It appears there is an ongoing need to develop awareness and skills amongst education practitioners to recognise and support the specific needs of female students with ASD.

Objectively speaking, the educational credentials of females with high functioning ASD should place them in a favourable position in the labour market. In reality, this study provides evidence that both unemployment and 'underemployment' (overeducation) are significant issues for this group. It has elucidated a number of 'typical' obstacles faced by women with ASD in workplace settings, and by implication has pointed to some of the basic accommodations and adjustments that can be implemented to support them. One of the most critical (and, to some extent, 'female-centric') factors would appear to be the availability and provision of part-time work. There is also an onus on employers to acknowledge that for female employees with ASD, cognitive functioning and emotional well-being can be inconsistent and unpredictable, and the risk of stress and burnout abnormally high. Giving clear instructions and allowing sufficient time to learn new procedures may be critical. More broadly, this study has identified the importance of appropriate career guidance and support for women with ASD, many of whom are skilled, motivated and ambitious, but require additional help if they are to realise their goals and reach their full potential in the world of work.

With regard to social experiences and social behaviour, this study has provided some tentative support for the 'masking' hypothesis outlined in the Introduction: the notion that women with high functioning ASD (seemingly more so than men) may seek to disguise their inherent struggles with social communication by means of learnt behaviour, including 'stock phrases' and normatively appropriate responses to particular scenarios. Although this can only be speculated from the current data, it is possible that this forms part of the reason why the women in this study were less likely than their male co-participants to have been offered social support (defined as support targeted at improving social skills and building friendships) during their time at school, and similarly why this type of support was less commonly offered than support for learning and behavioural needs.

Notably, participants whose ASD remained undiagnosed until age 18 or after were significantly less likely to have received school-based social support than those who received a diagnosis while still in full-time education. In contrast, levels of access to learning and behaviour support were comparable (though still restricted) between the pre- and post-18 diagnosis groups. This may be a further indication that the social impairments of females with high functioning ASD are the most likely aspect of their symptomatology to 'fall under the radar', especially if their ASD has not been formally identified.

Future research in this area might usefully be targeted towards a clearer understanding of the consequences of 'masking' behaviour for females with high functioning ASD, as well as a consideration of the value of teaching or facilitating the development of masking skills as a social support intervention.

There was some evidence to suggest that women in the study tended to be less socially engaged than their male co-participants: more content in their own company and less driven by the desire for friendships and romantic relationships. Nonetheless, these findings are relative to a large degree: still large proportions of women with high functioning ASD are struggling to make and maintain the social connections they desire. Furthermore, as evidenced by their comments regarding interpersonal 
interaction in the workplace, women with ASD may perhaps find the demands and disappointments of social communication more emotionally and psychologically burdensome than do men.

Overall, there is a common perception amongst women with high functioning ASD that their support needs tend to be overlooked or disregarded because they do not fit into conventional social constructions of 'disability', and are belied by a normal or above-average level of intelligence. Whilst on the whole women with high functioning ASD do not exhibit the same adaptive behaviour deficits as individuals with a global ID, there are many ways in which their everyday independence is restricted relative to the neurotypical population. Difficulties with high level information processing, flexible thinking, personal organisation, and interpersonal relating, compounded by ongoing mental health issues, can present challenges across many areas of everyday life. It is important that research continues to build a clearer picture of the diversity and complexity of challenges experienced by adult females with high functioning ASD, especially as the National Disability Insurance Scheme individualised funding packages are rolled out in Australia, providing the opportunity for service providers to work with adults to deliver personcentred supports.

\section{Study limitations}

The generalisability of the study findings is potentially limited by the following sample characteristics: (1) its self-selecting nature, (2) the above-average education levels of participants, (3) the trend towards adult rather than childhood diagnosis of ASD. Methodologically, a future study of this nature would be made more rigorous by inclusion of a measure to formally characterise the ASD symptomatology of the sample.

\section{Notes}

This study was approved by the [name of organisation removed for blinding purposes] Research Approvals Committee.

The authors declare that they have no conflict of interest.

\section{References}

ABS (2012). Job Search Experience. Cat. No. 6222.0, July. Canberra, ACT: Australian Bureau of Statistics.

ABS (2013). Labour Force. Cat. No. 6202.0, January. Canberra, ACT: Australian Bureau of Statistics.

ABS (2014). Gender Indicators. Cat. No. 4125.0, August. Canberra, ACT: Australian Bureau of Statistics.

Attwood, T. (2007). The complete guide to Asperger's Syndrome. London: Jessica Kingsley.

Autism Spectrum Australia (2013). We Belong: The experiences, aspirations and needs of adults with Asperger's Disorder and high functioning autism. Sydney: Autism Spectrum Australia.

Baron-Cohen, S., Cassidy, S., Auyeung, B., Allison, C., Achoukhi, M., Robertson, S., et al. (2014). Attenuation of Typical Sex Differences in 800 Adults with Autism vs. 3,900 Controls. Plos ONE, 9(7), 1-10.

Beardon, L., \& Edmonds, G. (2007). ASPECT consultancy report: A national report on the needs of adults with Asperger Syndrome. Sheffield: The Autism Centre, Sheffield Hallam University.

Black, D. J. (2013). The utilisation of human capital from education in Australian Labour Markets: Overeducation? Unpublished PhD thesis, University of Melbourne.

Ciampi, M. (2013). Navigating the female Aspergian mind. Annals of Psychotherapy \& Integrative Health, 16(2), 34-39.

Coombs, E., Brosnan, M., Bryant-Waugh, R., \& Skevington, S. M. (2011). An investigation into the relationship between eating disorder psychopathology and autistic symptomatology in a non-clinical sample. British Journal of Clinical Psychology, 50(3), 326-338.

Cross, D., Shaw, T., Hearn, L., Epstein, M., Monks, H., Lester, L., \& Thomas, L. 2009. Australian Covert 
Bullying Prevalence Study (ACBPS). Perth: Child Health Promotion Research Centre, Edith Cowan University.

Dworzynsky, K., Ronald, A., Bolton, P., \& Happe, F. (2012). How different are girls and boys above and below the diagnostic threshold for autism spectrum disorders? Journal of the American Academy of Child and Adolescent Psychiatry, 51(8), 788-797.

Fombonne, E., Quirke, S., \& Hagen, A. (2011). Epidemiology of pervasive developmental disorders. In Amaral, D. G., Dawson, G., \& Geschwind, D. H. (eds.), Autism Spectrum Disorders (pp. 90-111). New York: Oxford University Press.

Gould, J., \& Ashton-Smith, J. (2011). Missed diagnosis or misdiagnosis? Girls and women on the autism spectrum. Good Autism Practice, 12(1), 34-41.

Hambrook, D., Tchanturia, K., Schmidt, U., Russell, T., \& Treasure, J. (2008). Empathy, systemizing, and autistic traits in anorexia nervosa: A pilot study. British Journal of Clinical Psychology, 47(3), 335339.

Hartley, S. L., \& Sikora, D. M. (2009). Sex differences in autism spectrum disorder: An examination of developmental functioning, autistic symptoms, and coexisting behavior problems in toddlers. Journal of Autism and Developmental Disorders, 39(12), 1715-1722.

Head, A., McGillivray, J., \& Stokes, M. (2012). Gender differences in emotionality and sociability in children with autism spectrum disorders. Molecular Autism, 5(19), online: http://www.molecularautism.com/content/5/1/19

Holtmann, M., Bölte, S., \& Poustka, F. (2007). Autism spectrum disorders: sex differences in autistic behavior domains and coexisting psychopathology. Developmental Medicine and Child Neurology, 49(5), 361-366.

Kim, Y. S., Leventhal, B. L., Koh, Y. J., Fombonne, E., Laska, E., Lim, E. C., et al. (2011). Prevalence of autism spectrum disorders in a total population sample. American Journal of Psychiatry, 168, 904-912.

Kirkovski, M., Enticott, P., \& Fitzgerald, P. (2012). A review of the role of female gender in autism spectrum disorders. Journal of Autism \& Developmental Disorders, 43(11), 2584-2603.

Kreiser, N., \& White, S. (2014). ASD in females: are we overstating the gender difference in diagnosis? Clinical Child \& Family Psychology Review, 17(1), 67-84.

Lai, M.-C., Lombardo, M. V., Pasco, G., Ruigrok, A. N. V., Wheelwright, S. J., Sadek, S. A., et al. (2011). A behavioral comparison of male and female adults with high functioning autism spectrum conditions. PLOS ONE 6(6), e20835.

Mattila, M. L., Kielinen, M., Linna, S. L., Jussila, K., Ebeling, H., Bloigu, R. et al. (2011). Autism spectrum disorders according to DSM-IV-TR and comparison with DSM-5 draft criteria: An epidemiological study. Journal of the American Academy of Child \& Adolescent Psychiatry, 50(6), 583-592.

Mandy, W., Chilvers, R., Chowdhury, U., Salter, G., Seigal, A., Skuse, D. Sex differences in autism spectrum disorder: evidence from a large sample of children and adolescents. Journal of Autism \& Developmental Disorders, 42(7), 1304-1313.

McLennan, J. D., Lord, C., \& Schopler, E. (1993). Sex differences in higher functioning people with autism. Journal of Autism \& Developmental Disorders, 23(2), 217-227.

Pooni, J., Ninteman, A., Bryant-Waugh, R., Nicholls, D., \& Mandy, W. (2012). Investigating autism spectrum disorder and autistic traits in early onset eating disorder. International Journal of Eating Disorders, 45(4), 583-591.

Råstam, M. (2008). Eating disturbances in autism spectrum disorders with focus on adolescent and adult years. Clinical Neuropsychiatry, 5, 31-42. 
Rosenblatt, M. (2008). I Exist: The message from adults with autism in England. London: National Autistic Society.

Slade, T., Johnston, A., Teesson, M., Whiteford, H., Burgess, P., Pirkis, J., \& Saw, S. (2009). The mental health of Australians 2: Report on the 2007 National Survey of Mental Health and Wellbeing. Canberra: Department of Health and Ageing.

Van Wijngaarden-Cremers, P. J., van Eeten, E., Groen, W. B., Van Deurzen, P. A., Oosterling. I. J., \& Van der Gaag, R. J. (2014). Gender and age differences in the core triad of impairments in autism spectrum disorders: a systematic review and metaanalysis. Journal of Autism \& Developmental Disorders, 44(3), 627-635.

Whiteley, P., Todd, L., Carr, K., \& Shattock, P. (2010). Gender ratios in autism, Asperger syndrome and autism spectrum disorder. Autism Insights, 2, 17-24.

Wing, L. (1981). Sex ratios in early childhood autism and related conditions. Psychiatry Research, 5, 129137. 


\section{Appendix Table: Gender comparisons}

Note: Italicised entries denote sub-categories of the most recent heading. Percentages for these groupings are mutually exclusive (though may not sum to 100 due to rounding). Non-italicised entries denote mutually exclusive sub-questions related to the relevant heading, each of which is analysed in its own right.

\begin{tabular}{|c|c|c|c|}
\hline & $\begin{array}{r}\text { Females } \\
(n=82)\end{array}$ & $\begin{array}{r}\text { Males } \\
(n=200)\end{array}$ & Gender comparison \\
\hline Mental health & & & \\
\hline Frequent worry/stress (\%) & 82 & 79 & n.s. \\
\hline Mental health condition (\%) & 85 & 67 & $\chi^{2}=9.160, p<0.05$ \\
\hline Support needed for mental health (\%) & 73 & 65 & n.s. \\
\hline Receiving adequate support (\%) & 30 & 27 & n.s. \\
\hline \multicolumn{4}{|l|}{ Education } \\
\hline Completed Year 12/equivalent (\%) & 83 & 77 & n.s. \\
\hline Completed degree (\%) & 11 & 11 & n.s. \\
\hline Currently studying (\%) & 43 & 27 & $\chi^{2}=6.721, p<0.01$ \\
\hline Learning difficulties (\%) & 51 & 50 & n.s. \\
\hline Attention/concentration problems (\%) & 53 & 60 & n.s. \\
\hline Support needed for study skills (\%) & 38 & 39 & n.s. \\
\hline Support systems: best thing (\%)* & 32 & 22 & n.s. \\
\hline Support systems: worst thing $(\%)^{*}$ & 46 & 35 & n.s. \\
\hline Inadequate learning support (\%) & 51 & 46 & n.s. \\
\hline Inadequate behaviour support (\%) & 68 & 60 & n.s. \\
\hline Inadequate social support (\%) & 77 & 65 & $\chi^{2}=3.846, p=0.05$ \\
\hline Bullying: worst thing (\%)* & 50 & 49 & n.s. \\
\hline Social isolation: worst thing (\%)* & 37 & 34 & n.s. \\
\hline \multicolumn{4}{|l|}{ Employment } \\
\hline Current paid job (\%) & 62 & 50 & n.s. \\
\hline Full-time & 41 & 56 & \\
\hline Part-time & 60 & 44 & n.s. \\
\hline \multicolumn{4}{|l|}{ Occupational grouping (\%) } \\
\hline Community/personal service workers & 24 & 2 & \multirow{5}{*}{$\chi^{2}=19.063, p<0.01$} \\
\hline Clerical/administrative workers & 24 & 22 & \\
\hline Professionals & 22 & 22 & \\
\hline Technicians/trade workers & 12 & 12 & \\
\hline Other** & 17 & 41 & \\
\hline Overeducated (\%) & 55 & 42 & n.s. \\
\hline Social interaction: worst thing (\%)* & 60 & 40 & $\chi^{2}=7.419, p<0.05$ \\
\hline Receiving workplace support (\%) & 29 & 27 & n.s. \\
\hline Need more workplace support (\%) & 29 & 34 & n.s. \\
\hline \multicolumn{4}{|l|}{ Unemployment } \\
\hline Want a job (\%) & 56 & 67 & \multirow{3}{*}{$\chi^{2}=8.160, p<0.05$} \\
\hline Prefer full-time & 14 & 48 & \\
\hline Prefer part-time & 86 & 52 & \\
\hline \multicolumn{4}{|l|}{ Social experiences } \\
\hline Satisfied with social life (\%) & 80 & 77 & n.s. \\
\hline No social group/club, would like (\%) & 36 & 32 & n.s. \\
\hline No friendship group, would like (\%) & 32 & 41 & n.s. \\
\hline No mentor/befriender, would like (\%) & 32 & 37 & n.s. \\
\hline Prefer own company (\%) & 27 & 10 & $\chi^{2}=14.288, p<0.05$ \\
\hline Single: want dating support (\%) & 56 & 68 & n.s. \\
\hline Single: relationship/marriage a goal (\%) & 19 & 40 & $\chi^{2}=8.139, p<0.05$ \\
\hline Support needed for social skills (\%) & 62 & 60 & n.s. \\
\hline Support needed to deal with bullying (\%) & 44 & 51 & n.s. \\
\hline
\end{tabular}


* Statements appended with the word 'positive' denote a factor identified as a 'best thing' pertaining to the area in question (experiences of education or employment). Conversely, statements appended with the word 'negative' indicate that this factor was identified as a 'worst thing'.

** 'Other' categories represent summary groupings of additional response options. 